\title{
Generic Structure of Discussion Sections in ESP Research Articles across International and Iranian Journals
}

\author{
Masoud Khalili Sabet \\ English Language Department, University of Guilan, Rasht, Iran \\ E-mail: Sabetma2002@yahoo.com \\ Maryam Kazempouri (Corresponding author) \\ English Language Department, University of Guilan, Rasht, Iran \\ E-mail:m.kazempour67@gmail.com
}

Doi:10.7575/aiac.alls.v.6n.2p.87

Received: 19/11/2014

URL: http://dx.doi.org/10.7575/aiac.alls.v.6n.2p.87

Accepted: 29/01/2015

\begin{abstract}
Reviewing literature reveals that identifying generic structure of research articles (RAs) in different fields of study, especially ESP, has received much attention. The major purpose behind such trends of research has been raising researchers' awareness of the common conventions in writing RAs. Along with this universal trend, a lot of genre studies have been done in Iranian context; however, it seems that ESP RAs have not been paid due attention yet. Hence this study aimed at investigating the generic structure of ESP RAs in international and Iranian journals. Applying Kanoksilapatham's (2007) model to the compiled corpus, it was found that contextualizing the study (Move 1) and consolidating results (Move 2) were the obligatory moves in Discussion section of ESP RAs across international and Iranian journals. Evaluation of the findings was a new step found in international Discussion sections but absent in Iranian ones. Related discussion of these findings prepares the researchers for publishing in international and Iranian ESP journals.
\end{abstract}

Keywords: ESP, Discussion section, Move, Step, Author presence, Generic structure

\section{Introduction}

Generic structure of RAs across different fields of study has received much attention in recent years (e.g., Swales, 1990, 2004; Kanoksilapatham, 2007; Khany \& Tazik, 2010, 2011; Hirano, 2009; Flowerdew \& Wan, 2010). The main purpose of all these researchers was discussing the generic structure of different sections of RAs (Bonn \& Swales, 2007). The central implication of these studies were proving standard framework for non-native or novice researchers before trying for publishing in different scientific journals. Holmes (1997) relates this interest to the pedagogical concerns of academicians and their tendency towards developing standard and satisfactory models which analyze scientific texts and enhancing non-natives' ability in understanding and producing such texts. To reach such aims, generic structure of different sections of RAs have been analyzed e.g., Abstract (Samraj, 2005), Introduction (Swales, 1990; Khany \& Tazik, 2010); Results (Brett, 1994; Fallah, 2004), and Discussion (Holmes, 1997; Khani \& Tazik, 2011). The findings supposed to be effective for non-native speakers (NNSs) who aspire to become proficient writers among different members of their discourse community. The genre analysis approach tends to identify the move-step structure of RAs across different discourse communities. Yang and Allison (2003) defines move as a function of a specific segment of the texts in a general level while steps are very specific rhetorical means used to manifest and realize the move functions. In more details, Bhatia (2001) defined moves as "Rhetorical instruments that realize a subset of specific communicative purposes associated with a genre, and as such they are interpreted in the context of the communicative purposes of the genre in question" (p. 84). Steps were also defined by Dudley-Evans and St. John (1998) as "a lower level text unit than the move that provides a detailed perspective on the options open to the writer in setting out the moves" (p. 89). Kanoksilapatham (2005) and Swales (1990) as well as Yang and Allison (2003) state that moves and steps in a text make it coherent and well-organized. They help to produce a text with smoothly related sentences which logically follow a single purpose. Therefore, writers need to know the nature of moves and steps in order to present sets of purposes in a written text. Flowerdew and Wan (2010) reported that having a proficient knowledge of English as well as move-step structure of RAs can highly contribute to the publication of RAs in prestigious journals. Among different sections of RAs, Flowerdew (2001) believes that Discussion section is the part where the novice writers may face problems. He maintains that in this section the writers need to evaluate their findings and provide evidence for their implications. Therefore, they need to have knowledge of organizing this section in advance.

To represent the overall schematic structure of Discussion section in RAs, various models have been offered (e.g., Hopkins \& Dudley-Evans, 1988; Berkenkotter \& Huckin, 1995; Yang \& Allison, 2003; Kanoksilapatham, 2007). Hopkins \& Dudley-Evans's (1988) model was derived from the analysis of Discussion sections of MSc dissertations and 
biology, and articles on irrigation and drainage. They found that about eleven moves were present in this section which included in their model. They were: background information, statement of results, (un) expected outcomes, reference to previous research(comparison), explanation of unsatisfactory results, exemplification, deduction, hypothesis, reference to previous research (support), recommendation, and justification. Berkenkotter and Huckin (1995) suggest that moves of Discussion section can be occupying a niche, (re) establishing the field, and establishing additional territory. These moves are in fact the same as those reported for Introduction sections. Yang and Allison (2003) analyzed the move sequence of Discussion sections in Applied Linguistic RAs. They observed the following moves for Discussion sections: background information, reporting results, summarizing results, commenting on results, interpreting and comparing with the literature, accounting for results, evaluating, summarizing the result, evaluating the study, and suggestions for further research and pedagogical implications. From their view, Discussion sections in Applied Linguistic mostly tend to comment on the results as obligatory moves.

Through applying these models, various studies have been conducted on the Discussion section of RAs across many fields of study. For instance, Holmes (1997), in a corpus consisted of thirty RAs taken from the fields of History, Political Science, and Sociology, analyzed the rhetorical moves of Discussion sections of these RAs. His findings indicated some similarities and differences in the move structure of Discussion sections in the corpus. Resemblances of rhetorical structure of social science and natural science Discussion sections were interesting findings which could have precious implications for ESP teaching. Peacock (2002), using Dudley-Evans's (1994) model, analyzed the rhetorical moves of Discussion section in RAs in seven disciplines, including Physics, Biology, Environmental Science, Business, Language and Linguistics, Public and Social Administration, and Law. Based on the analysis, a number of remarkable moves were found. However, he reported that no move was obligatory across all the Discussion sections. Moves such as Claim, Finding, Reference to previous research, and Recommendations were the most frequent moves. Based on the findings, Peacock (2002) suggested that the findings may provide insights into the teaching of research article writing.

There are similar studies conducted in Iranian context. For instance, Amirian, Kassaian, and Tavakoli (2008) analyzed the Discussion sections of applied linguistics RAs (RAs) from the perspective of genre. Their corpus includes, the Discussion sections of English RAs published in international English journals of the field and Persian RAs published in professional Persian journals of the same field in order to find the differentiating factors between published English and Persian RAs at the level of move schemata. They found that the most conspicuous difference between English and EFL Discussion sections were the separation between the "results" and "Discussion" sections. The English texts separated the two sections in content while, in the EFL corpus, blending of the "results" and the "Discussions" sections was sometimes observed. Based on the obtained data, they suggested the following moves as the extended model of moves identified in English corpus: Presenting background, Reference to the previous research, Statement of aims, Finding, Explanation, Reference to previous research, Restatement of findings, Reference to previous research, Limitation of the study, and Recommendation for further research.

In another study, Khani and Tazik (2010), drawing on Swales (1990), Kanoksilapatham (2007), and Nwogu's (1991) models and using top-down and bottom-up analytic procedures, tried to compare the generic structure of Introduction and Discussion sections of international and Iranian local (IL) RAs in sub-disciplines of Applied Linguistics. They reported that their findings showed no significant differences regarding the obligatory moves of Introduction section across two corpora; however, significant differences in Discussion section were revealed. They discussed that these results can be helpful for both experienced and novice researchers in reporting their research findings in a permissible style.

Reviewing the above reported studies indicated that there are not universal trends in writing the Discussion section in RAs. There appeared to be variety of recommendations for writing this section which implies the discipline specificity of writing conventions. Moreover, it is also observed that the ESP field has not received much attention among Iranian researchers. This lack of comprehensive studies, on the one hand, and the importance of familiarizing Iranian researchers with the acceptable writing convention, on the other hand, necessitates doing research on the generic structure of Discussion sections of ESP RAs across International and Iranian journals. Therefore, in this study, based on the move analytic model proposed by Kanoksilapatham (2007) the move structure of the Discussion sections across two corpora was analyzed.

\section{The Study}

\subsection{The corpus of the study}

The corpus of the present study comprised of 60 RAs (Table 1) taken from three Iranian and three international journals (IJs). For the consistency of the results, all the articles chosen for this study were published in 2008 to 2014 by authors of different nationalities in major academic journals. The articles from mentioned journals were randomly selected from the table of contents of the journals. The chosen Iranian ESP journals are Iranian journal of Biotechnology (IJB), Journal of Agricultural Sciences and technology (JAST), and archives of Iranian Medicine Journal (AIMJ). These journals cover a good number of RAs written in Biotechnology, Agriculture, and Medical Sciences, respectively. ESP International journals include the Agriculture, Ecosystems and Environment journal (AEE), Journal of Biotechnology (JB) and Medical Hypotheses (MH). The journals chosen for the study were all prestigious journals in the field with high credibility among researchers.

From the Table of contents of IJs and ILJs, ten articles from each journal written in the sub-disciplines of ESP were selected based on the following criterion: 
- The selected RAs followed AIMRDC structures

- They were published in some of the major subfield of ESP.

- The selected RAs were written in ILJs and IJs.

- The selected RAs were complete RAs, with a length of 4000 to 8000 words.

Table 1. Number (No.) of ESP journals used in this study

\begin{tabular}{lcc}
\hline Iranian Local ESP Journals & Impact Factor & No. of articles \\
\hline Journal of Agricultural Sciences and technology & 0.679 & 10 \\
Iranian Journal of Biotechnology & 0.536 & 10 \\
Archive of Iranian Medicine & 1.222 & 10 \\
& & \\
International ESP Journals & & 10 \\
\hline Agriculture, Ecosystems and Environment journal & 3.869 & 10 \\
Journal of Biotechnology & 3.221 & 10 \\
Medical Hypotheses & 1.196 & \\
\hline
\end{tabular}

In Kanoksilapatham's (2005) study, 60 RAs were used as a representative sample. With this particular sample, her study yielded significant results, which were generalizable to the biochemistry RA genre. Altogether, 60 RAs as used in the current study should be an adequate and complete representation of the ESP RAs from each context (local and international contexts) and they should yield significant findings.

\subsection{Analytical framework}

As it was noted, the model used for the analysis of move structure of this study was Kanoksilapatham's (2007) model. Kanoksilapatham (2007), analyzed a corpus of Biochemistry RAs written in Thai and English. Results of the analysis have revealed a four-move structure for the Discussion sections. The identified moves are: contextualizing the study, consolidating results, stating limitations, and suggesting further research. The moves and steps identified by Kanoksilapatham (2007) are presented in Table 2.

Table 2. Kanoksilapatham (2007) model for Discussion sections of ESP RAs

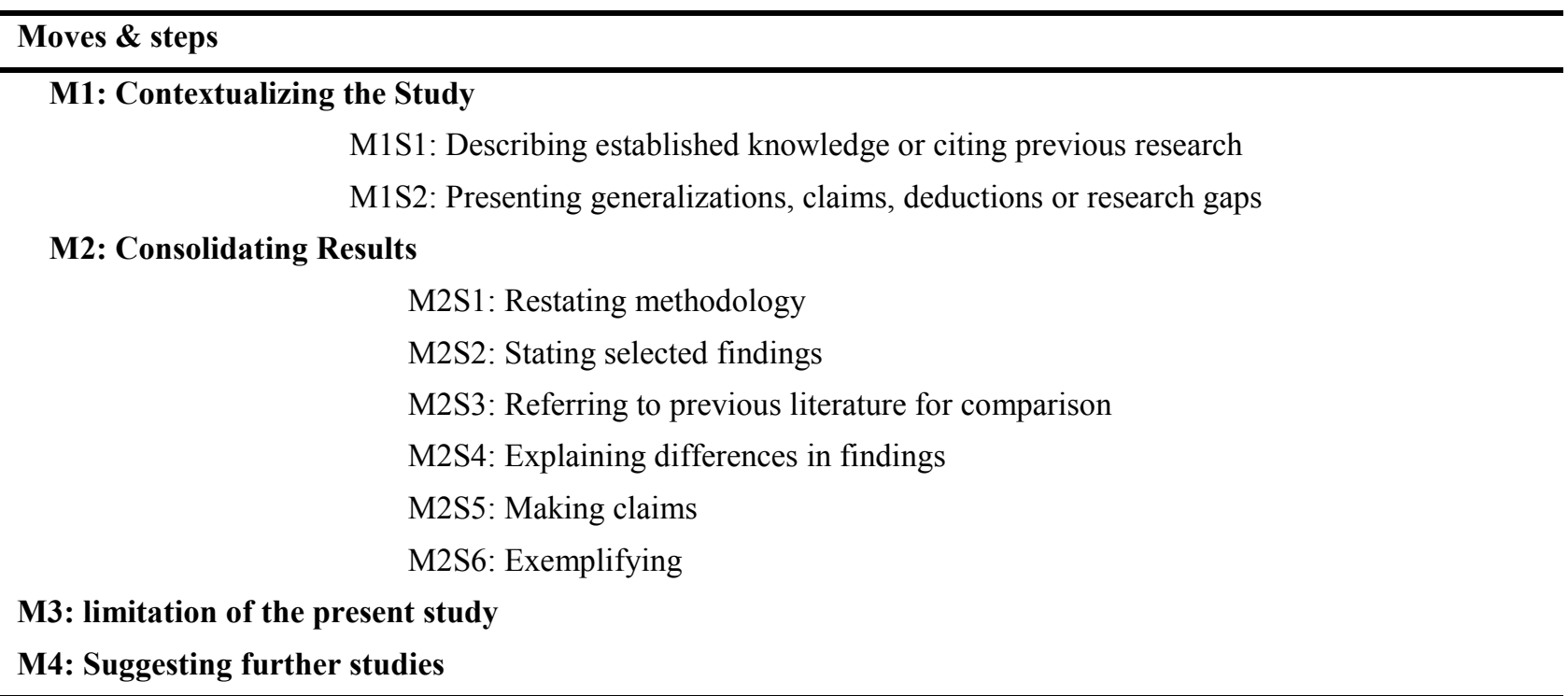

Note: M: move, S: step

The first move of Discussion section included in Kanoksilapatham's (2007) model is contextualizing the study via describing the established knowledge in the field and making topic generalization. The second and the major move, is consolidating the results. This move consists of six steps which proceed from restating methodology, stating the main findings, commenting on the findings by comparing and contrasting them with previous research, to making claims and exemplifying. The last two moves of Discussion section are stating limitations of the study and suggesting for further research.

The reasons for the selection of this framework for this study were (1) the model has been the last revision of the framework proposed by Kanoksilapatham (2005), thus it can be accepted as a reliable model (2) the model can have a 
strong theoretical basis (3) according to Kanoksilapatham (2007), the moves and steps included in the model can significantly reveal the different strategies that experienced and novice writers serve for the presentation of their research perspectives and finally (4) the model was specifically designed for ESP RAs.

\section{Results}

\subsection{Communicative moves across ESP RAs}

To addressed the preferred rhetorical patterns in ESP RAs written in international and ILJs and the similarities and differences of the organizational patterns followed by the writers in two groups, the presence or absence of the identified moves and steps included in the employed models of the study have been examined. Regarding the move analytical model proposed by Kanoksilapatham (2007) and based on the data obtained from the precise analysis of Discussion sections of ESP RAs, the obligatory and optional moves and steps served by international and IJs as well as the overall structure of RAs published in different journals can be implied. The obligatory and optional moves followed in international and Iranian local RAs have been identified and presented in Tables 4.1.

Table 3. Obligatory and optional moves and steps in Iranian local and international ESP journals

\begin{tabular}{|c|c|c|c|c|c|c|}
\hline \multirow[b]{2}{*}{ Moves \& Steps } & \multicolumn{3}{|c|}{ Iranian Local ESP Journals } & \multicolumn{3}{|c|}{ International ESP Journals } \\
\hline & $\mathbf{F}$ & Rate (\%) & Frequently used in: & $\mathbf{F}$ & Rate & Frequently used in: \\
\hline M1S1 & 17 & $56.66^{*}$ & AIMJ & 19 & $63.33^{*}$ & AEE, MH \\
\hline M1S2 & 16 & $53.33^{*}$ & JAST & 15 & $50^{*}$ & AEE \\
\hline M2S1 & 19 & $63.33^{*}$ & AIMJ, IJB & 20 & $66.66^{*}$ & JB \\
\hline M2S2 & 30 & $100^{*}$ & All Journals & 30 & $100^{*}$ & All Journals \\
\hline M2S3 & 30 & $100^{*}$ & All Journals & 27 & $90^{*}$ & AEE, JB \\
\hline M2S4 & 15 & $50^{*}$ & JAST, AIMJ & 10 & 33.33 & AEE \\
\hline M2S5 & 30 & $100^{*}$ & All Journals & 28 & $93.33^{*}$ & JB \\
\hline M2S6 & 12 & 40 & AIMJ & 24 & $80^{*}$ & AEE, JB \\
\hline M3 & 8 & 26.66 & AIMJ & 6 & 20 & $\mathrm{MH}$ \\
\hline M4 & 10 & 33.33 & AIMJ & 7 & 23.33 & JB \\
\hline
\end{tabular}

Note: M: move, S: step, IJB: Iranian journal of Biotechnology, JAST: Journal of Agricultural Sciences and technology, AIMJ: Archives of Iranian Medicine Journal, AEE: Agriculture, Ecosystems and Environment journal, JB: Journal of Biotechnology, MH: Medical Hypotheses

*The step is obligatory

According to Table 3, the obligatory moves which ILJs followed in their RAs were M1S1 (56.66\%), M1S2 (53.33\%), M2S1 (63.33\%), M2S2 (100\%), and M2S3 (100\%), M2S4 (50\%), and M2S5 (100\%). International ESP journals, on the other hand, structured with obligatory moves such as M1S1 (63.33\%), M1S2 (50\%), M2S1 (66.66\%), M2S2 (100\%), M2S3 (90\%), M2S5 (93.33\%). As the results showed, generic structure of ESP RAs across ILJs and international ESP journals were similar, except for M2S4 which occurred in 50\% of IL RAs, and M2S6 which occurred in $80 \%$ of international journals as obligatory steps. In the Discussion section, M2S2, M2S3 in ILJs and M2S2 in international journals were present in the total number of ESP RAs in both corpora.

Although descriptive analysis indicated that international and Iranian local ESP RAs, except for M2S4 and M2S6 of the model, had similar move structures, some discrepancies have been observed. To see if these discrepancies are significant, the data were subjected to the chi-square analysis (Table 4).

Table 4. Chi-square analysis for the significance of inter-differences of step frequencies in ESP RAs across IL and international journals

\begin{tabular}{|c|c|c|c|c|c|c|c|c|c|c|}
\hline \multicolumn{11}{|c|}{ Moves and steps of Discussion sections } \\
\hline & M1S1 & M1S2 & $\mathrm{M} 2 \mathrm{~S} 1$ & M2S2 & $\mathrm{M} 2 \mathrm{~S} 3$ & M2S4 & M2S5 & M2S6 & M3 & M4 \\
\hline$\chi^{2}$ & .11 & .03 & .02 & .00 & .15 & 1.00 & .06 & 4.00 & .28 & .52 \\
\hline Sig. & .73 & .85 & .87 & .00 & .69 & .31 & 79 & $.04 *$ & .59 & .46 \\
\hline
\end{tabular}

Note. $\chi 2$ : Chi-square, Sig.: significance

$* \mathrm{p}<0.05$ 
As Table 4 shows, no significant differences, except in M2S6 $(\chi 2=4.00$, Sig. $=.04, \mathrm{P}<.05)$ which is an optional step in ILJs but an obligatory step in international ones, were observed between international and Iranian local ESP RAs.

Although general comparison of move structures of ESP RAs testified the similar obligatory moves across international and ILJs, comparing moves and steps utilized in each ESP sub-field across both corpora can give more reliable results. To have such findings, move frequencies of each ESP sub-field across international and ILJs have been compared and contrasted (Table 5). Table 5 represents the one by one comparison of move frequencies in similar ESP subfields across international and ILJs based on the moves and steps provided in the model proposed by Kanoksilapatham (2007). As the given Table showed, occurrences of moves across the international and ILJs were different. However, Chi-square statistical analysis run for determining the significance of these discrepancies did not reveal any significant differences. Therefore, it seems that members of the same discourse community across different contexts follow the same rhetorical structure in their RAs.

Table 5. comparison of move frequencies and Chi-square results for the significance of these frequencies in ESP international and ILJs

\begin{tabular}{|c|c|c|c|c|c|c|c|c|c|}
\hline \multirow[b]{3}{*}{ Moves \& Steps } & \multicolumn{9}{|c|}{ ESP Journals } \\
\hline & \multicolumn{3}{|c|}{ Medical Science } & \multicolumn{3}{|c|}{ Agriculture } & \multicolumn{3}{|c|}{ Biotechnology } \\
\hline & IL & $\mathbf{I}$ & $\chi^{2}$ & IL & $\mathbf{I}$ & $\chi^{2}$ & IL & $\mathbf{I}$ & $\chi^{2}$ \\
\hline M1S1 & 7 & 5 & .33 & 6 & 7 & .07 & 4 & 7 & .14 \\
\hline M1S2 & 5 & 4 & .11 & 6 & 6 & 0 & 5 & 5 & 0 \\
\hline M2S1 & 7 & 7 & 0 & 5 & 4 & .11 & 6 & 9 & .60 \\
\hline M2S2 & 10 & 10 & 0 & 10 & 10 & 0 & 10 & 10 & 0 \\
\hline $\mathrm{M} 2 \mathrm{~S} 3$ & 9 & 7 & .25 & 10 & 10 & 0 & 10 & 10 & 0 \\
\hline M2S4 & 6 & 3 & 1.00 & 6 & 5 & .09 & 3 & 2 & .20 \\
\hline M2S5 & 10 & 9 & .05 & 10 & 9 & .05 & 10 & 10 & 0 \\
\hline M2S6 & 5 & 6 & .09 & 4 & 9 & 1.92 & 3 & 9 & 3.00 \\
\hline M3 & 5 & 3 & .50 & 2 & 1 & .33 & 1 & 2 & .33 \\
\hline M4 & 7 & 2 & 2.7 & 3 & 1 & 1.00 & 0 & 4 & 0 \\
\hline
\end{tabular}

Note: IL: Iranian Local journals, I: International journals, M: move, S: step

$\chi 2$ : Chi-square, $\mathrm{P}<0.05$

As it was found, inter-difference analysis of move structure of international and Iranian local RAs testify the similarity of rhetorical structure of ESP RAs across both contexts.

\subsection{New steps found in ESP RAs}

In Iranian local RAs, three new steps were found in Discussion section and added to the second move of Kanoksilapatham's (2007) model, i.e. consolidating results. Although these steps have been used by ESP authors, none of them were present in more than fifteen (50\%) RAs; hence, all of them were optional steps (Table 6). Similarly, three new steps were identified in the Discussion section of international RAs. All the new steps were present in move two and in contrast to the steps found in IL RAs, one of these steps, evaluation of the results, occurred in $50 \%$ of RAs, as a result, it was an obligatory step.

Table 6. N (number) and rate (\%) of new steps found in ESP RAs of IL and international journals

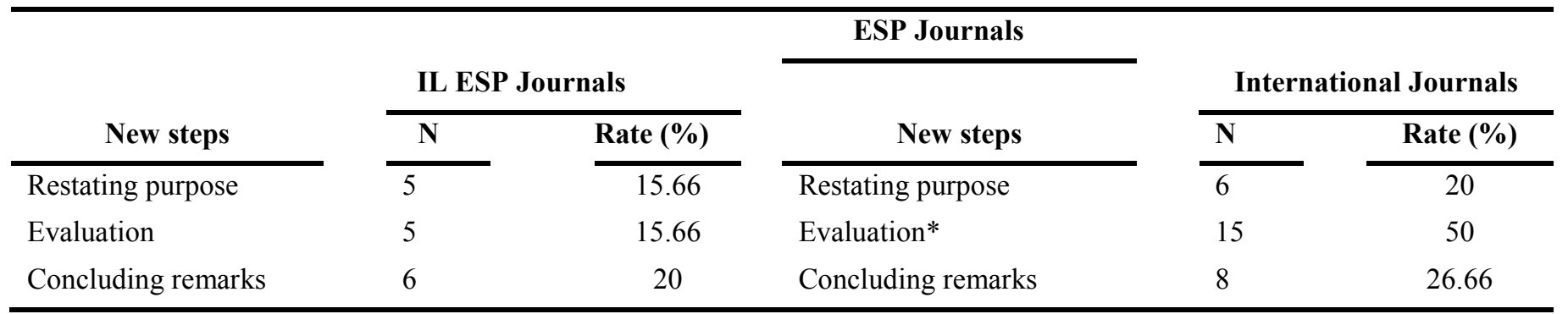

Note: IL: Iranian Local journals, *: indicates that the step is obligatory 


\section{Discussion}

Discussion section of RAs as a place of stating and discussing the research findings, comparing new findings with previous ones, and where the researchers dare to make claims, is an important and salient section in RAs. Analyzing the generic structure of this section has been under the focus of many researchers (Holmes, 1997; Biria \& Tahririan, 1997; Peacock, 2002; Fallahi \& Erzi, 2003). Results of these studies have led to the enumeration of different models for analyzing rhetoric structure of the Discussion section. Kanoksilapatham's (2007) model used in this study is one of these famous move analytic models. This model consists of 4 moves. Applying Kanoksilapatham's (2007) model in two corpora, M1 and M2 were the obligatory moves in ESP RAs. The two steps of M1, which contain describing established knowledge or citing previous research and presenting generalizations, claims, deductions or research gaps, were observed to be obligatory among both corpora. Therefore, findings were in line with Kanoksilapatham (2007) who suggests that Discussion section of RAs starts with "contextualizing the study". (Ex. 1 \& 2)

EX. 1: The distal radius is an uncommon site for benign tumors but it is the third most common site of occurrence of giant cell tumors $[1,2]$. Cortical breakthrough or pathologic fracture is often present with extra compartmental tumor extension. (AIMJ, 2010, p. 5)

EX. 2: The chemical reduction of porphyrin to porphyrinogen involves the addition of six hydrogen atoms to the porphyrin molecule: one to each of the four meso carbons and one to each of two pyrrole nitrogens. (JB, 2011, p. 78).

Across international and Iranian local ESP RAs, M2S1, M2S2, M2S3, and M2S5 were the obligatory steps. It seems that writers of both corpora may feel that restating methodology is necessary to be mentioned as a reminder for the readers. M2S2, "stating selected findings," as an obligatory step, was present in $100 \%$ of international and Iranian local RAs. Thus, it can be concluded that all the researchers make it essential to state the main findings in this section. M2S3 was also found to be obligatory in both groups of RAs. This move was present in $100 \%$ of Iranian local RAs and in $90 \%$ of international ESP RAs. It shows that all the ESP researchers, are eager to compare their findings with previous ones for the purpose of supporting or rejecting them. Results of these analyses, especially for Iranian local RAs, are in line with Falah (2004). She reported that although there were differences in frequency of steps across two international and Iranian local RAs, M2S2 and M2S3 (ex. 3 and 4) were the only obligatory steps in M2 across two corpora. She also stated that since the M2S2 was more frequent across two corpora, it can be the core element of the Discussion section of the RAs.

EX. 3: Results suggested that weed seed predation may be enhanced by maintaining a high and temporally extended vegetation cover. (MH, 2010, p. 15)

EX. 4: The present research offers a number of molecular tools suitable for proving olive oil authenticity. These tools provide a reliable protocol for DNA extraction from cold pressed olive oil and protocols to recognize the genetic background' of the oil by means of SSRs amplification. (IJB, 2010, p. 30)

M2S4 which states the "explaining differences in findings" was found to be an obligatory step in M2 of IL ESP RAs $(50 \%)$ while it was regarded as an optional step among international counterparts (33.33\%) (Ex. 5). It seems that IL ESP RAs put their efforts on explaining in detailed differences in findings. The claims on such different results make the findings more clear and justifiable.

EX. 5: Recurrence rates of giant cell tumors are higher in the distal radius than at other longbone sites. This is probably due to the anatomical structure of the distal radius $[2,4]$. The rate of local recurrence in the current series was low (only three of fifteen patients), but it is four times more than Mankin's or Bianchi's study. The reason may be that the rate of recurrent patients in our study who became candidates for reconstruction comprised $70 \%$ of the study population and patients who had had a primary giant-cell tumor comprised only $30 \%$ of our cases.

M2S6 which is "exemplifying" was an obligatory step among international ESP RAs (80\%) but an optional step among IL ESP RAs (40\%). Based on these findings, it can be discussed that international ESP RAs make it mandatory for the writers to justify and explain their findings through exemplifying. This strategy can be very helpful for understating the findings.

EX. 6: Annual and perennial weeds that were common in the arable field margins, for example, C. arvense, E. repens, F. officinalis, and Urtica dioica, were most frequent at the field edge of the road verges. (AEE, 2012, p. 261)

Along with top-down analysis of RAs, based on the given model suggested by Kanoksilapatham (2007), in bottom-up phase, all the moves followed in two corpora were collected. In this phase, some new steps used by local and international writers were found. However, in ESP international Discussions, evaluation as a step which was present in $50 \%$ of the RAs was found to be an obligatory step (ex. 7). This step was recommended by Yang and Allison (2003) in M2 of Discussion section, commenting on results. Nevertheless, it was ignored in the model used in this study.

EX. 7: The selectivity of the optimized conditions for converting porphyrin to porphyrinogen implies that further hydrogenation to disrupt the aromaticity of the pyrrole rings and to reduce the carbonyls requires more stringent conditions. (JB, 2012, p. 77)

All in all, it was shown that obligatory moves used in international and ILJs ESP RAs were the same; however, some differences in the use of steps that manifest these moves were observed. For instance, ESP international authors tended to explain differences in findings as an optional strategy in discussing their findings while Iranian local ESP RAs make it mandatory to use this step in Discussion sections. In contrast, "exemplifying" has been an optional strategy in IL ESP RAs but it is an obligatory strategy in international RAs. 
It was found that M3 and M4 included in Kanoksilapatham's (2007) model were not used obligatorily by the authors in both international and local RAs. Therefore, it is concluded that stating limitations of the study and suggesting further research are not regarded as mandatory in accepting an ESP RA for publication. In other words, ESP writers may choose different strategies for closing their RAs. These strategies may be what are included in the model or some concluding remarks. Nevertheless, none of these strategies are obligatory across the two corpora. Although some variations in the order of proposed moves and steps were observed, comparing the Kanoksilapatham's (2007) model and the results obtained after its application in the corpus of this study indicated that this model can be reliable in manifestation of the generic structure of ESP RAs. Because of the diversity of the fields analyzed, it seems that a combination of new and previous findings, as the results of this study showed, can be more reliable and generalizable across different contexts.

Regarding the obligatory moves, the generic structure of Discussion sections of ESP RAs were the same though the steps used to manifest the presence of these moves were not the same. In conclusion, it seems that Iranian local authors respectively followed "contextualizing the study and consolidating results" moves in their Discussion sections. International ESP writers, on the other hand, showed the same tendencies in Discussion sections, in addition to a new step added to "consolidating results". To manifest the structure of Discussion sections across both corpora, the established model is given in Table 7 below.

Table 7. Overall structure of Discussion sections in Iranian local and international ESP RAs

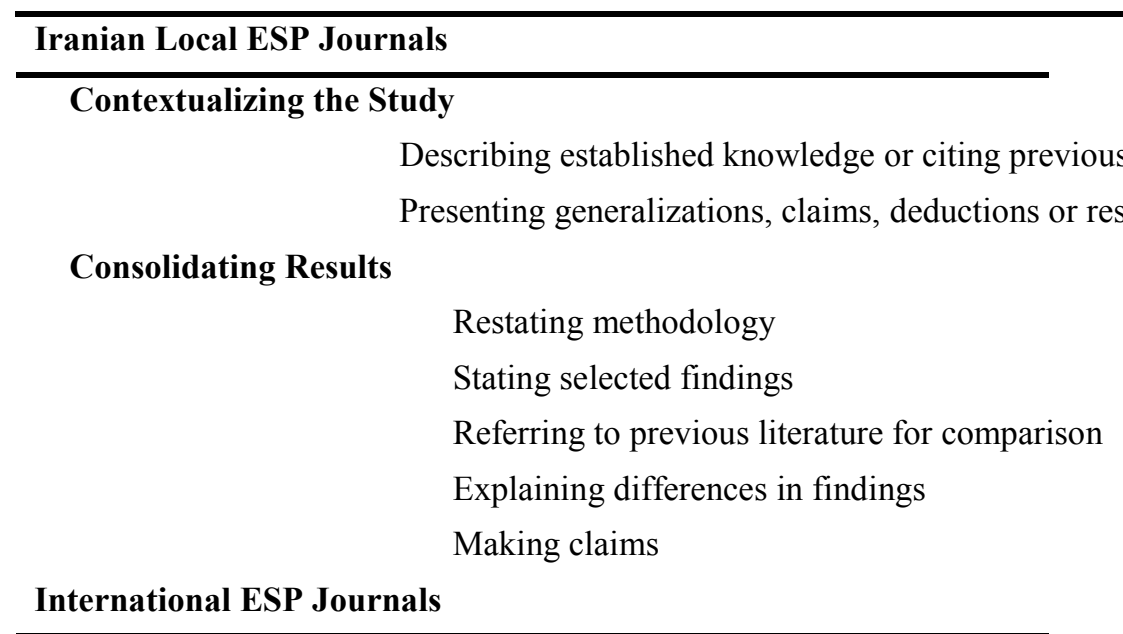

\title{
Contextualizing the Study
}

Describing established knowledge or citing previous research

Presenting generalizations, claims, deductions or research gaps

\section{Consolidating Results}

\author{
Restating methodology \\ Stating selected findings \\ Referring to previous literature for comparison \\ Evaluation of the findings* \\ Making claims \\ Exemplifying
}

\begin{abstract}
*New added step
The stability of Kanoksilapatham's (2007) model over Discussion sections in ESP RAs are in line with similar studies done with this framework e.g., Tazik (2009), Khani and Tazik (2011). They reported that this framework can be a good model for composing Discussion section in ESP RAs. The tendency of International towards evaluating their findings was also reported in Folowerdew and Wan (2009). They found that the major difference between RAs published in prestigious international journals inherited in the steps such as evaluation of the results.
\end{abstract}

\subsection{Pedagogical implications}

Findings of the study have some implications for second language writing teachers, ESP researchers and instructors, and ESP students. Language writing teachers must be aware of the fact that first and second languages have significant differences at the level of rhetorical organization. Therefore, they should assign those tasks and materials for the students whose accomplishment requires the precise focus on the rhetorical structures and various genres of writing. For example, they can give their students a separate section of an article and ask them to write an outline of the way materials are presented. 
In writing academic genres in a second language, teachers should raise their students' awareness of the conventions set by the discourse community for which they are writing. The students need to know that every discourse community, ESP as the concern of this study, might have specific styles in writing; hence, they need to be familiar with various styles and guidelines accepted and suggested by the manual publishers in each particular journal. Results of this study can be used as ready-to-use templates available for most of the communicative purposes of the academic writers in the fields of ESP.

Regarding the examined model, results of this study revealed some differences between international and ILJs. Findings can be helpful for Iranian local researchers especially for advanced EFL learners, who are seeking success in academic writing in their future careers, and for ESP scholars who might need their research published in English journals. Activities based on the results of this study might begin with students providing two sets of RA Discussion sections published in their discipline, from journals that they are motivated to read, one written in an ILJ and the other derived from an international journal. They, then, can compare and contrast different strategies served in writing a RA Discussion section. Students can also do so by doing some exercises in which they are asked to reorder scrambled sentences into appropriate order to form a RA.

In addition to the awareness of generic structure of RAs, language components can also be helpful in developing acceptable academic texts. One of these components can be vocabularies which writers in different discourse communities use in their texts. Respectively, Shaabani and Tazik (2014) found that academic vocabularies are essential and important in the quality of the papers and their acceptance by the experts in different discourse communities. They suggested that explicit teaching of academic vocabularies can be very helpful for the academic writers.

\section{References}

Amirian, Z., Kassaian, Z., \& Tavakoli, M. (2008). Genre Analysis: An Investigation of the Discussion Sections of Applied Linguistics RAs. The Asian ESP Journal, 4 (1), 39-63.

Biria, R., \& Tahririan, M. H. (1997). Communicative conventions in Discussion discourse. IJAL, 13(3), 1-11.

Brett, P. (1994). A genre analysis of the results section of sociology articles. English for Specific Purposes, 13, 47-59.

Berkenkotter, C., \& Huckin, T. N. (1995). Genre knowledge in disciplinary communication: Cognition/ culture/ power. Hillsdale, NJ: Lawrence Erlbaum.

Bhatia, V. K. (2001). Analyzing genre: some conceptual issues. In M. Hewings (Ed.), academic writing context (pp. 7992). Birmingham: University of Birmingham.

Bonn, S., \& Swales, J. M. (2007). English and French journal abstracts in the language sciences: Three exploratory studies. Journal of English for Academic Purposes, 6, 93-108.

Dudley-Evans, T. (1994). Genre analysis: An approach to text analysis in ESP. In M. Couthard (ED.), Advances in written text analysis (pp. 219-228). London: Routledge.

Dudley-Evans, A., \& St. John, M. J. (1998). Developments in English for Specific purposes. Cambridge: Cambridge University Press.

Fallah, S. (2004). A contrastive genre analysis of results and discussion sections of applied linguistics research articles by native and non-native English speakers with respect to evaluative entities and ascribed values. Unpublished Master's thesis, University of Teacher Training, Tehran, Iran.

Fallahi, M. M., \& Erzi, M. (2003). Genre analysis in language teaching: An investigation of the structure of the Discussion section of language- teaching-journal articles. $I J A L, 6(1), 69-81$.

Flowerdew, J. (2001). Attitudes of journal editors to nonnative speaker contributions. TESOL Quarterly, 35(1), 121150 .

Flowerdew, J., \& Wan, A. (2009). The linguistic and the contextual in applied genre analysis: The case of the company audit report. English for Specific Purposes, 29(2), 78-93.

Hirano, E. (2009). RA Introductions in English for specific purposes: A comparison between Brazilian Portuguese and English. English for Specific Purposes, 28, 240-250.

Holmes, R. (1997). Genre analysis, and the social sciences: An investigation of the structure of RA Discussion sections in three disciplines. English for Specific Purposes, 16(4), 321-337.

Hopkins, A., \& Dudley-Evans, A. (1988). A genre-based investigation of the Discussion sections in articles and dissertations. English for Specific Purposes, 7, 113-122.

Kanoksilapatham, B. (2005). Rhetorical structure of biochemistry RAs. English for Specific Purposes, 24, $269-292$.

Kanoksilapatham, B. (2007). Rhetorical moves in biochemistry RAs. In D. Biber, U. Connor, \& T. A. Upton (Eds.). Discourse on the move: Using corpus analysis to describe discourse structure. Studies in corpus linguistics, 28, (pp. 73-119). Amsterdam: John Benjamins.

Khany, R., \& Tazik, K. (2010). A Comparative Study of Introduction and Discussion sections of Sub-disciplines of Applied Linguistics Research Articles. Journal of Applied Language Studies (JALS), 1 (2), 97-122. 
Khany, R., \& Tazik, K. (2011). The Relationship between Rhetorical moves and Lexical Cohesion Patterns; the case of Introduction and Discussion sections of Local and International Research Articles. Journal of English Language Teaching and Learning, 53, 71-95.

Nwogu, K. N. (1991). Structure of science popularizations: A genre-based analysis approach to the schema of popularized medical texts. English for Specific Purposes, 10, 111-123.

Peacock, M. (2002). Communicative moves in the discussion section of research articles. System, 30, 479-497. http://dx.doi.org/10.1016/S0346-251X(02)00050-7.

Samraj, B. (2005). An exploration of a genre set: Research article abstracts and introductions in two disciplines. English for Specific Purposes, 24, 141-156.

Shabani, M. B., \& Tazik, K. (2014). Coxhead's AWL across ESP and Asian EFL Journal Research Articles (RAs): A Corpus-Based Lexical Study. Procedia - Social and Behavioral Sciences, 98, 1722 - 1728.

Swales, J. M. (1990). Genre analysis: English in academic and research settings. Cambridge: Cambridge University Press.

Swales, J. M. (2004). Research genres: Explorations and applications. Cambridge: Cambridge University Press.

Yang, R., \& Allison, D. (2003). Research articles in applied linguistics: Moving from results to conclusions. English for Specific Purposes, 22, 365-385. 